\title{
Delivering on George Eisenbarth's Visionary Pursuit of Understanding Pathogenesis and Prevention of Type 1 Diabetes
}

\author{
Richard A. Insel, MD
}

\begin{abstract}
George Eisenbarth's pioneering and visionary research has provided a critical foundation that will be built on in the years ahead as we progress toward prevention of type 1 diabetes. His almost 30-year old model that type 1 diabetes was a chronic and predictable autoimmune disease with multiple identifiable progressive stages with a potential for interventions to prevent progression to symptomatic diabetes has stood the test of time. To deliver on the Eisenbarth vision and his "unfinished journey," the field needs: (1) to improve detection of risk of type 1 diabetes, (2) to improve staging and prediction of progression, (3) to perform smaller, shorter, practical, and an increased number of prevention clinical trials, and (4) to increase awareness of the potential for risk detection, staging, and prevention of type 1 diabetes and benefit/risk of prevention.
\end{abstract}

\section{Introduction}

$\mathbf{T}$ HE UNTIMELY DEATH OF George Eisenbarth, MD, PhD, in 2012 ended a legendary career that had a major focus around preventing type 1 diabetes. Dr. Eisenbarth combined an inquisitive mind, a tireless and tenacious quest, and a passionate zeal to understand the pathogenesis of type $1 \mathrm{di}-$ abetes, characterize its natural history, develop improved diagnostics, and search for safe and effective type 1 diabetes preventive therapies. ${ }^{1-3}$ His pioneering and visionary research has provided the critical foundation that will be built on in the years ahead as we progress toward prevention of the disease.

Throughout his career, Dr. Eisenbarth was honored with multiple prestigious awards, including the Juvenile Diabetes Research Foundation (JDRF) David Rumbough Scientific award in 1997, the American Diabetes Association Banting Medal for Scientific Achievement Award in 2009, and the JDRF Mary Tyler Moore and S. Robert Levine Excellence in Clinical Research Award in 2012. To further honor Dr. Eisenbarth's amazing legacy, to cherish the Eisenbarth ethos, and to spur others to carry on his vision and quest, JDRF announced the creation in 2013 of the JDRF George Eisenbarth Award for Type 1 Diabetes Prevention to recognize outstanding advances in the prevention of type 1 diabetes. In a testimony to his recognition outside of the field of diabetes, George received the Pasteur-Weizman/Servier International Prize and Tribute in 2006, one of the most important international prizes that is awarded only every 3 years in recognition of the efforts of a researcher renowned for his or her major role in a biomedical discovery leading to a therapeutic application. Beyond these awards and tributes, Dr. Eisenbarth was above all a "gentleman" scientist-generous, humble, collegial, collaborative, and catalytic - who was beloved by his colleagues, as witnessed by the outpouring of memorial tributes, ${ }^{4-6}$ including the multiple tributes in this Festschrift for George in Diabetes Technology $\mathcal{E}$ Therapeutics. Contributing to his lasting legacy are the numerous internationally prominent diabetes scientists who George trained over several decades, including many who contributed to this Festschrift. George was a longtime friend of JDRF, and the Foundation remains indebted to George for his lifetime contribution to type 1 diabetes and to JDRF.

Almost 30 years ago, George demonstrated that type 1 diabetes was a chronic and predictable autoimmune disease with multiple stages that could be identified using serum autoantibodies and measurements of $\beta$-cell function and that would permit prediction of progression. ${ }^{7-9}$ With relatively minor modifications, these seminal insights have stood the test of time ${ }^{10,11}$ and have provided the critical framework for our thinking today about type 1 diabetes pathogenesis. His model has served as the basis for the current immune-based therapeutic and prevention type 1 diabetes clinical trials. Demonstration that type 1 diabetes was not an acute but a chronic disease raised the possibility of intervention to prevent its progression both during the period after the onset of

JDRF, New York, New York. 
$\beta$-cell specific autoimmunity when type 1 diabetes is asymptomatic and in new-onset type 1 diabetes. In fact, based on those seminal insights, George immediately pursued some of the first immunotherapy clinical trials for type 1 diabetes, ${ }^{12}$ using agents that are still being evaluated in the clinic today. ${ }^{13,14}$ Over 20 years ago, George also extended his therapeutic approaches to exploration of oral tolerance with demonstration of the ability of oral insulin to delay diabetes in the NOD mouse, ${ }^{15}$ which was a forerunner of the Diabetes Prevention Trial Type 1 (DPT-1) oral insulin trial and the follow-on TrialNet oral insulin trial ${ }^{16}$ and PrePOINT oral insulin trial. ${ }^{17}$

Based on his model, George realized that a better understanding of the genetics and environmental etiologies of type 1 diabetes was required, and he focused his efforts on characterizing both. ${ }^{18,19}$ With his colleague Marian Rewers, George created the Diabetes Autoimmunity Study in the Young (DAISY) study at the Barbara Davis Center for Diabetes in Denver, CO, that applied genetic and immunologic prediction of type 1 diabetes to infants followed from birth. ${ }^{19}$ The DAISY studies have provided profound insights into pathogenesis of childhood-onset type 1 diabetes and represent one of the pilot studies that led to The Environmental Determinants of Diabetes in the Young (TEDDY) study, which has screened over 400,000 newborns from six sites in the United States and Europe for genetic risk of type 1 diabetes and is now following approximately 8,000 at-risk children during their first 15 years of life to identify environmental etiologies of type 1 diabetes. ${ }^{20}$ In recognizing that more precise approaches for detection of $\beta$-cell-specific autoimmunity were required, the Eisenbarth laboratory became one of the premier centers for development of assays to measure type 1 diabetes autoantibodies, which have served to date as the basis of all immunology-focused clinical trials for type 1 diabetes. The recent development by the Eisenbarth laboratory of nonradioactive autoantibody assays to distinguish persistent insulin autoantibodies with differential risk of type 1 diabetes progression will likely alter approaches to risk detection. ${ }^{21}$

Dr. Eisenbarth championed the concept that insulin was the central pioneer autoantigen for both the generation of destructive T-cell responses and the therapeutic induction of protective T-cell immunity in type 1 diabetes. He also believed that the pathogenic response to insulin was "hard-wired" not only in the NOD mouse model of type 1 diabetes but also in a subset of humans with a specific genetic background and would show conserved $\mathrm{T}$-cell receptor usage in its recognition of the insulin B:9-23 peptide, a major epitope targeted by $\mathrm{T}$ cells in type 1 diabetes. ${ }^{22}$ His recent research with colleagues has confirmed these ideas by demonstrating that a unique trimolecular complex (insulin:9-23 peptide, the T-cell receptor, and MHC class II molecules) is likely generated only in the pancreas and the draining pancreatic lymph nodes and thus allows escape from the thymus of autoreactive $\mathrm{T}$ cells able to cause type 1 diabetes. ${ }^{23,24}$ As a direct result of these insights, novel type 1 diabetes therapeutic preventive and curative approaches targeting this unique structure have been developed by George and colleagues. ${ }^{25}$

In his 2009 Banting lecture, Dr. Eisenbarth spoke of his "unfinished journey" to prevent diabetes and his unrelenting belief that "chronic active insulitis will become a treatable entity similar to chronic active hepatitis." ${ }^{1}$ To deliver on
George's vision in a timely manner, the field needs to refine its strategy:

\section{To Improve Detection of Risk of Type 1 Diabetes}

The number of subjects being screened for risk of type 1 diabetes need to be increased, more cost-effective approaches for risk detection are required, and more specific assays of risk will need to be developed. TrialNet is annually screening approximately 13,000-14,000 new first- and second-degree relatives of individuals with type 1 diabetes, ${ }^{26}$ which represents a relatively small proportion of at-risk relatives. New approaches need to be developed to increase awareness of risk in relatives, who have a 10 - to $>100$-fold higher risk than the background population. ${ }^{27}$ Social media should be exploited to communicate both degree of risk and options for risk screening in relatives of affected individuals. Empowering and equipping families to conduct at-home screening may prove possible. More specific approaches to autoantibody detection that are predictive of risk of developing type 1 diabetes must be exploited, ${ }^{21}$ and there may be novel approaches to detect risk even prior to the development of autoantibodies. ${ }^{28}$ To date, there is a lack of demonstration that progression of chronic active insulitis in the type 1 diabetes atrisk setting can be slowed, which if demonstrated would catalyze interest from the type 1 diabetes community in having relatives screened and increase the number of subjects who are available for enrollment in clinical trials. Relatives of affected individuals account for only $10-15 \%$ of newly diagnosed type 1 diabetes. To increase the pool size of subjects for trials, cost-effective population-based approaches for screening using assays for autoantibodies, genetics, and/or omicsbased approaches need to be further explored.

\section{To Improve Staging and Prediction of Progression}

The pathogenesis and natural history of human type 1 diabetes are still not well elucidated. We do not understand the basis of the variable period between onset of $\beta$-cell-specific autoimmunity and overt type 1 diabetes. It is unclear whether type 1 diabetes is a relapsing-remitting disease during that period of time. If such is occurring, then we need to better understand the basis of both relapses and remissions, and we need to direct preventive therapies to specifically induce and maintain remissions. Type 1 diabetes is a heterogeneous disease, and we lack tools to fully dissect this heterogeneity. Additional biomarkers need to be developed to stage the disease more accurately and to predict rate of progression, which as described below can aid in subject stratification for clinical trials.

\section{To Perform Smaller, Shorter, Practical, and an Increased Number of Prevention Clinical Trials}

The long-term clinical goal with interventions in the atrisk setting of type 1 diabetes should be to prevent insulin dependence, which for even as short a period as 1 year should be considered clinically impactful, especially in children and adolescents. To optimize clinical trial design for prevention trials, smaller and shorter mechanistic-based exploratory clinical research should be conducted initially to determine whether drugs and biologics are engaging potentially relevant targets and pathways in specific stages of 
type 1 diabetes prior to launching larger size and longer efficacy trials. When efficacy trials are performed, they should be designed initially as shorter trials with use of intermediate end points that occur in the natural history of progression to insulin dependence. These trials will require both improved prognostic biomarkers for staging, predicting progression, and clinical trial stratification and also predictive biomarkers to enhance selection of subjects more likely to respond to a specific intervention due to their physiology or disease characteristics and to assess therapeutic responses. Adaptive trials should be used to more efficiently investigate delay of insulin dependence and to explore the use of combination therapies that are added sequentially. As Dr. Eisenbarth noted, ${ }^{1}$ it is quite likely that combination therapies will be required to confer robust, durable prevention of insulin dependence after the onset of $\beta$-cell-specific autoimmunity. To prove effective, combination therapies may require addressing not only adaptive autoimmunity, but also targeting inflammation and innate immunity, $\beta$-cell stress, and abnormal metabolic control. In light of the earlier age of onset of type 1 diabetes ${ }^{29}$ and the development of $\beta$-cell-specific autoimmunity beginning in the first few years of life, ${ }^{30,31}$ preventive interventions must be safe and practical for use in young children.

\section{To Increase Awareness of the Potential for Risk Detection, Staging, and Prevention of Type 1 Diabetes and Benefit/Risk of Prevention}

In concert with the previous three goals, it is critical to begin to precondition and inform the wider community of regulatory authorities, payers, healthcare providers, and families affected by type 1 diabetes of the progress that has been made to date and that will continue in detecting risk, staging the disease, and intervening to slow disease progression. JDRF has prioritized a public health orientation to both primary and secondary type 1 diabetes prevention, representing prevention before and after the onset of $\beta$-cell autoimmunity respectively, with targeting of not only relatives of type 1 diabetes-affected individuals, but targeting the entire childhood population with either risk screening for secondary prevention or intervention without risk screening for primary prevention. ${ }^{32-35}$ Regulatory authorities and payers need to be educated with respect to benefit/risk of preventive interventions in the at-risk setting and need to hear from individuals and families affected by type 1 diabetes and type 1 diabetes patient advocacy organizations. Academia, industry, regulatory authorities, payers, healthcare providers, patients and their families, and patient advocacy groups will need to work together more effectively to deliver on prevention of type 1 diabetes.

\section{Conclusions}

George Eisenbarth pointed the way, and his research has provided a foundation for prevention of type 1 diabetes. His vision has been prescient and viable for the last 25 years, his impressive legacy will be lasting, and his "unfinished journey" will be realized if we remain steadfast and strategic.

\section{Author Disclosure Statement}

No competing financial interests exist.

\section{References}

1. Eisenbarth GS: Banting Lecture 2009: an unfinished journey: molecular pathogenesis to prevention of type 1A. Diabetes 2010;59:759-774.

2. Bluestone JA, Herold K, Eisenbarth G: Genetics, pathogenesis and clinical interventions in type 1 diabetes. Nature 2010;464:1293-1300.

3. Eisenbarth GS: Prevention of type 1A diabetes mellitus. Endocr Pract 2012;18:745-749.

4. Atkinson MA: George S. Eisenbarth, 1947-2012. Diabetologia 2013;56:435-438.

5. Hitman GA: Type 1 diabetes from bench to bedside; a dedication to George Eisenbarth. Diabet Med 2013; 30:133.

6. Pugliese A, Skyler JS: George S. Eisenbarth: insulin and type 1 diabetes. Diabetes Care 2013;36:1437-1442.

7. Srikanta S, Ganda OP, Soeldner JS, Eisenbarth GS: Firstdegree relatives of patients with type I diabetes mellitus. Islet-cell antibodies and abnormal insulin secretion. $\mathrm{N}$ Engl J Med 1985;313:461-464.

8. Soeldner JS, Tuttleman M, Srikanta S, Ganda OP, Eisenbarth GS: Insulin-dependent diabetes mellitus and autoimmunity: islet cell autoantibodies, insulin autoantibodies, and beta-cell failure. N Engl J Med 1985;313:893-894.

9. Eisenbarth GS: Type I diabetes mellitus. A chronic autoimmune disease. N Engl J Med 1986;314:1360-1368.

10. Atkinson MA, Eisenbarth GS: Type 1 diabetes: new perspectives on disease pathogenesis and treatment. Lancet 2001;358:221-229.

11. Atkinson MA, Eisenbarth G, Michels A: Type 1 diabetes-a season of change for concepts regarding the epidemiology, pathogenesis, treatment and prospects for disease attenuation. Lancet 2013 (accepted for publication).

12. Eisenbarth GS, Srikanta S, Jackson RA, Rabinowe SL, Dolinar R, Haynes BF, Morris MA: Anti-thymocyte globulin and prednisone immunotherapy of recent onset type I diabetes mellitus. Diabetes Res 1985;2:271-276.

13. Study of Thymoglobulin to Arrest Newly Diagnosed Type 1 Diabetes (START). Clinical Trials.gov Identifier NCT00515099. http://ClinicalTrials.gov/ (accessed April 16, 2013).

14. Reversing Type 1 Diabetes After It Is Established. ClinicalTrials.gov Identifier NCT01106157. http://ClinicalTrials.gov/ (accessed April 16, 2013).

15. Zhang ZJ, Davidson L, Eisenbarth G, Weiner HL: Suppression of diabetes in NOD mice by oral administration of porcine insulin. Proc Natl Acad Sci U S A 1991;88:1025210256.

16. Oral Insulin for Prevention of Diabetes in Relatives at Risk for Type 1 Diabetes Mellitus. ClinicalTrials.gov Identifier NCT00419562. http://ClinicalTrials.gov/ (accessed April 16, 2013).

17. Achenbach P, Barker J, Bonifacio E; Pre-POINT Study Group: Modulating the natural history of type 1 diabetes in children at high genetic risk by mucosal insulin immunization. Curr Diab Rep 2008;8:87-93.

18. Ide A, Eisenbarth GS: Genetic susceptibility in type 1 diabetes and its associated autoimmune disorders. Rev Endocr Metab Disord 2003;4:243-253.

19. Rewers M, Bugawan TL, Norris JM, Blair A, Beaty B, Hoffman M, McDuffie RS Jr, Hamman RF, Klingensmith G, Eisenbarth GS, Erlich HA: Newborn screening for HLA markers associated with IDDM: Diabetes Autoimmunity Study in the Young (DAISY). Diabetologia 1996;39:807-812. 
20. TEDDY Study Group: The Environmental Determinants of Diabetes in the Young (TEDDY) study: study design. Pediatr Diabetes 2007;8:286-298.

21. Yu L, Miao D, Scrimgeour L, Johnson K, Rewers M, Eisenbarth GS: Distinguishing persistent insulin autoantibodies with differential risk: nonradioactive bivalent proinsulin/ insulin autoantibody assay. Diabetes 2012;61:179-186.

22. Homann D, Eisenbarth GS: An immunologic homunculus for type 1 diabetes. J Clin Invest 2006;116:1212-1215.

23. Stadinski BD, Zhang L, Crawford F, Marrack P, Eisenbarth GS, Kappler JW: Diabetogenic $\mathrm{T}$ cells recognize insulin bound to IAg7 in an unexpected, weakly binding register. Proc Natl Acad Sci U S A 2010;107:10978-10983.

24. Stadinski B, Kappler J, Eisenbarth GS: Molecular targeting of islet autoantigens. Immunity 2010;32:446-456.

25. Michels AW, Ostrov DA, Zhang L, Nakayama M, Fuse M, McDaniel K, Roep BO, Gottlieb PA, Atkinson MA, Eisenbarth GS: Structure-based selection of small molecules to alter allele-specific MHC class II antigen presentation. J Immunol 2011;187:5921-5930.

26. Mahon JL, Sosenko JM, Rafkin-Mervis L, Krause-Steinrauf H, Lachin JM, Thompson C, Bingley PJ, Bonifacio E, Palmer JP, Eisenbarth GS, Wolfsdorf J, Skyler JS; TrialNet Natural History Committee; Type 1 Diabetes TrialNet Study Group: The TrialNet Natural History Study of the Development of Type 1 Diabetes: objectives, design, and initial results. Pediatr Diabetes 2009;10:97-104.

27. Ziegler AG, Nepom GT: Prediction and pathogenesis in type 1 diabetes. Immunity 2010;32:468-478.

28. Oresic M, Simell S, Sysi-Aho M, Näntö-Salonen K, SeppänenLaakso T, Parikka V, Katajamaa M, Hekkala A, Mattila I, Keskinen P, Yetukuri L, Reinikainen A, Lähde J, Suortti T, Hakalax J, Simell T, Hyöty H, Veijola R, Ilonen J, Lahesmaa R, Knip M, Simell O: Dysregulation of lipid and amino acid metabolism precedes islet autoimmunity in children who later progress to type 1 diabetes. J Exp Med 2008;205:29752984.

29. Harjutsalo V, Sjöberg L, Tuomilehto J: Time trends in the incidence of type 1 diabetes in Finnish children: a cohort study. Lancet 2008;371:1777-1782.

30. Ziegler AG, Bonifacio E; BABYDIAB-BABYDIET Study Group: Age-related islet autoantibody incidence in offspring of patients with type 1 diabetes. Diabetologia 2012;55:19371943.

31. Parikka V, Näntö-Salonen $\mathrm{K}$, Saarinen $\mathrm{M}$, Simell T, Ilonen J, Hyöty H, Veijola R, Knip M, Simell O: Early seroconversion and rapidly increasing autoantibody concentrations predict prepubertal manifestation of type 1 diabetes in children at genetic risk. Diabetologia 2012;55:1926-1936.

32. Insel RA, Deecher DC, Brewer J: Perspectives in diabetes: Juvenile Diabetes Research Foundation: mission, strategy, and priorities. Diabetes 2012;61:30-35.

33. Staeva TP, Chatenoud L, Insel R, Atkinson MA: Recent lessons learned from prevention and recent-onset type 1 diabetes immunotherapy trials. Diabetes 2013;62:9-17.

34. Insel R: Speculation on prevention of type 1 diabetes. In: Taylor K, Hyöty H, Toniolo A, Zuckerman A, eds. Diabetes and Viruses. New York: Springer Science, 2012:339-3480.

35. http://jdrf.org/blog/2011/preventing-type-1-diabetes-theleadership-role-of-jdrf/ (accessed April 16, 2013).

Address correspondence to: Richard A. Insel, MD

JDRF

26 Broadway, $14^{\text {th }}$ Floor New York, NY 10004

E-mail: rinsel@jdrf.org 